\title{
SOBRE LAS FORMAS DE REPRODUCCIÓN DEL DISCURSO AJENO EN ALGUNOS TEXTOS PERIODÍSTICOS DE LA PRENSA ITALIANA Y ESPAÑOLA
}

\author{
María Trinidad Frías Lebrón \\ Universidad de Cagliari (Italia)
}

\begin{abstract}
Resumen: En este trabajo se abordan algunos textos periodísticos italianos y españoles desde una perspectiva pragmática, como fenómeno de comunicación que sirve de punto de partida para analizar la polifonía del mensaje periodístico. Se estudian por tanto, la multiplicidad de voces a las que da acogida dicho texto y los procedimientos de cita que aparecen en el mismo, delimitando los principales mecanismos de reproducción del discurso ajeno que subyacen en ambas culturas periodísticas, para resaltar, donde proceda, las diferencias y analogías.
\end{abstract}

Palabras clave: Discurso referido, Polifonía, Pragmática, Emisor mediático, Neutralidad.

\begin{abstract}
In this work we focus on some Italian and Spanish journalistic articles from a pragmatic approach, as a communication phenomenon that becomes a starting point to analyze polyphony in the journalistic message. The essay encores a Multiplicity of voices that are an essential part of this kind of text, but also an attempt to assess the procedures of reported speech that underlies journalistic cultures, in order to stand out, where possible, differences and analogies. Keywords: Reported Speech, Polyphony, Pragmatics, Mass Media speaker, Neutrality.
\end{abstract}

\section{INTRODUCCIÓN}

En el texto periodístico ocurre con frecuencia que el periodista, el sujeto locutor, se contamina del estilo y las peculiaridades expresivas del discurso ajeno que reproduce, elaborando al final un producto aparentemente propio, pero que en realidad es la síntesis perfecta de su propia subjetividad sumada a la representación de los modos de hablar, del sujeto cuyo discurso se reproduce. Nos proponemos analizar la multiplicidad de voces a las que da acogida el texto periodístico y los procedimientos de cita que aparecen en el mismo, prestando atención no sólo a los modelos sintagmáticos de reproducción más tradicionales, es decir el 
Discurso Directo y el Discurso Indirecto, sino también a las citas mixtas o citas implícitas, cuya frecuencia en los textos objeto de estudio es incluso mayor de lo que se podría pensar a priori. Una atenta "lectura entre líneas" nos permitirá descubrir que, en sus artículos, los periodistas dialogan con otros sujetos, articulando palabras propias y ajenas que van impregnándose recíprocamente de matices ideológicos, tanto acordes como contrarios.

Todo mensaje, también el periodístico, es un mensaje intencional y lo que se afirma no es independiente del modo de hacerlo, por lo que está sujeto a interpretación. ${ }^{1} \mathrm{Al}$ pronunciar un enunciado nos proponemos ejercer sobre la voluntad del receptor, que puede ser real - como en la conversación directa entre dos interlocutores - o posible - como en los textos periodísticos, en los que se pretende persuadir de la veracidad del contenido. Aunque desde una perspectiva formal uno de los rasgos más habituales de la enunciación periodística sea la búsqueda de un efecto de neutralidad mediante la eliminación de las marcas del enunciador a través del Discurso Referido, observaremos que pocas veces se respeta la tan pretendida objetividad que invocan los manuales de estilo periodístico.

En las páginas que siguen se intentará analizar este interesante aspecto, prestando especial atención a la comparación entre algunos textos periodísticos en lengua italiana y en lengua española para delimitar las prácticas del periodismo escrito en ambos países y los mecanismos de reproducción del discurso ajeno que subyacen en ambas culturas periodísticas desde los parámetros de la lingüística pragmática y del análisis del discurso. En nuestro análisis hemos preferido restringir el ámbito de estudio a los textos periodísticos que utilizan el medio escrito como soporte para su propagación porque son los que nos permiten analizar de forma más clara y evidente las formas de producir y atribuir el discurso de las fuentes.

Para la parte española se han utilizado sobre todo el diario El País y el diario El Mundo y para los italianos diarios de tirada nacional como La Repubblica, Il Giornale, Il Corriere della Sera así como diarios regionales, l'Unione Sarda e Il Sardegna, todos ellos representativos de las tendencias políticas y sociales de ambos países.

Por su especial relevancia en la vida política de Italia y España los textos abarcan el periodo comprendido entre los meses de marzo y abril de 2008, considerando que en dicho arco temporal, en ambos países, se celebraron elecciones generales, con la renovación del ejecutivo. La elección no es casual; como es bien sabido, en fases conflictivas, como las campañas electorales, los medios de comunicación se convierten en instrumentos fundamentales para reproducir y transmitir la información que procede de los discursos ajenos de las fuentes interesadas, en este caso, de los políticos. Es entonces cuando los periódicos tratan de ejercer una mayor influencia sobre la opinión de los lectores para acercarlos y

1 Véase la Teoría de la Argumentación de Anscombre y Ducrot (1994). 
adscribirlos a un determinado partido político, a una concreta orientación política haciéndose más patente, si cabe, la fuerte carga de subjetividad que conlleva la escritura periodística.

\section{LA POLIFONÍA Y EL DISCURSO REFERIDO}

Según el DRAE la polifonía se define como "el conjunto de sonidos simultáneos en que cada uno expresa su idea musical, pero formando con los demás un todo armónico." Desde el parámetro de la Pragmática este importante concepto de la Teoría de la Argumentación pone de relieve que en la enunciación concurren diferentes voces que se superponen, aunque aparentemente se trate del mismo sujeto. ${ }^{2}$

Asimismo y directamente relacionado con la idea de la multiplicidad del sujeto enunciativo podemos afirmar que todo discurso tiene ecos de otros, forma parte de un entramado discursivo en el que cada pieza encaja a la perfección precisamente porque remite a otros discursos. Incluso sin hacer uso de mecanismos explícitos de cita podemos afirmar que cualquier discurso está íntimamente ligado a otros: lejos de ser una enunciación aislada del contexto social y cultural las huellas de dicho contexto se materializan en todo momento y el texto las acomoda en sí mismo. De alguna manera las palabras que usamos no son nuestras, sino repeticiones involuntarias de discursos que organizamos en función de nuestras necesidades comunicativas.

El texto periodístico no se sustrae a dicha heterogeneidad pues es producto de la intersección de varias voces. La polifonía forma parte esencial de su naturaleza, de ahí que la escritura periodística pueda definirse como un espacio interdiscursivo, en el que se entrelazan y articulan diversas voces y tonalidades. Asistimos, por lo tanto, a un entrecruzamiento de voces y textos, cuyo origen y naturaleza diversas generan el producto final, la noticia, no resultando siempre fácil reconocer las diferentes personas enunciativas, puesto que éstas a menudo se tejen en la red de forma tan velada que dificultan notablemente la labor de discernir quién dice, afirma, sostiene, supone, etc.

La posibilidad de reproducir lo dicho por otros es un recurso universal del lenguaje y de extrema importancia en el periodismo, donde el sujeto reproductor regula la entrada de dichas voces recurriendo a diversas modalidades de atribución, a través de las citas directas e indirectas. El Discurso Referido (a partir de ahora DR) es un procedimiento por el que se integran la voz o voces de otros en una determinada unidad textual. En otras palabras, el DR reproduce

2 Inspirándose en las aportaciones de M. Bajtín y otros autores, O. Ducrot elabora una teoría de la enunciación para la cual el concepto de sujeto unitario se dividiría en tres. Por un lado, el sujeto empírico que sería el productor real del enunciado, y por el otro, entrarían en escena el locutor, una ficción discursiva al que se le debe imputar la responsabilidad del enunciado, y el enunciador, la persona cuyo punto de vista presenta los acontecimientos expresados en los enunciados. Véase Ducrot (1984). 
un determinado enunciado proferido por un sujeto ajeno en otro momento, situación y/o contexto dentro de un acto de enunciación completamente diverso. El enunciado extrapolado informa acerca de lo que ese otro sujeto dice, piensa u opina, dotando a la escritura periodística de dinamismo a la vez que aporta indicios precisos y directos del discurso originario. Gracias a esto último, el DR riega el discurso periodístico con notas de seguridad y certeza y autoridad, es decir, de elevada correspondencia entre el acto de habla original y su reproducción.

No existe un único procedimiento para incorporar las voces de otros en el propio discurso. El DR abarca varias modalidades sintagmáticas, algunas más tradicionales o básicas como el Discurso Directo o Indirecto, otras complementarias o aglutinadoras de éstas como el Discurso Indirecto Libre, las citas mixtas y las citas no expresas, entre otras. Existe, por lo tanto, toda una gama de formas de reproducción tanto explícitas como implícitas que se combinan en un mismo texto. El estudio de este vasto panorama discursivo constituye uno de los puntos de interés en el marco del análisis del discurso de los medios de comunicación por escrito.

\section{FORMAS DE REPRODUCCIÓN DEL DISCURSO REFERIDO}

\subsection{Discurso Directo y Discurso Indirecto}

En el Discurso Directo (a partir de ahora DD) se reproducen las palabras de otros dejándolas aparentemente de la misma manera en que fueron proferidas. Algunos estudiosos llegan a considerarlo la manifestación más pura de la polifonia precisamente porque en apariencia en él se halla afincada la literalidad, la reproducción fiel de las palabras de un "enunciador primitivo". ${ }^{3}$ Su característica principal es que lo dicho se reproduce textualmente recurriendo al entrecomillado. Sin embargo, el carácter de literalidad del DD es una ilusión, porque en el preciso momento en que se cita, el discurso original sufre numerosas manipulaciones del sentido, de la fuerza ilocutiva que tenía originariamente y de la situación de partida, debido a la descontextualización y sucesiva recontextualización por parte de la voz citante, que lo ajustará a sus propias necesidades discursivas y argumentativas. La aparente autenticidad del DD hace que el locutor reproductor asuma las veces de portavoz objetivo, lo cual induce espontáneamente a creer que el enunciado referido es exactamente como fue proferido. Ahora bien el uso formal de las comillas, por muy preciso que sea, no elimina la eventualidad de que las frases citadas sean aquellas con las que el periodista está más de acuerdo, poniendo en realidad en boca de sus enunciadores su propia opinión. Así lo vemos claramente en la siguiente secuencia:

(1) La poligamia, como recuerda Mariano Rajoy, es ilegal en España. Gaspar Llamazares añadiría: "e indeseable en política". (El Paîs, 7-03-08, 24)

3 Gutiérrez Ordóñez (2003: 54). 
Desde el punto de vista sintáctico en el DD suele existir una expresión introductora (el marco) que puede reducirse a un verbo de comunicación (verba dicendi), aunque no es tampoco infrecuente la omisión de dicho verbo, posibilidad ésta que admite sólo dicha modalidad de reproducción. En el ejemplo siguiente, extraído de un titular, vemos que el marco se reduce a la mención del sujeto que profiere la cita. Normalmente dichas citas se señalan gráficamente con comillas, dos puntos o entre guiones, aunque en la prensa italiana puede omitirse todo: los dos puntos, las comillas, el verbo introductor, el sujeto enunciador. Así no ha de extrañar que, con frecuencia, la cita directa se introduzca simplemente mediante una coma:

(2) Bertinotti, sí a chi occupa le case. (La Repubblica, 26-03-08, 6)

No falta tampoco la desaparición total del marco, sobre todo en los titulares, como en el siguiente ejemplo de L'Unione Sarda, en el que se oculta el responsable de la declaración:

(3) “Nell'Isola c'è una sinistra molto solida”. (L'Unione Sarda, 08-04-08, 5)

¿Quién dice la frase? ¿De qué isla se habla? Este tipo de omisiones, más habitual en los textos periodísticos italianos que en los españoles, atiende a una estrategia periodística que induce al lector a leer el resto del texto, para poder contextualizar esas palabras y así descubrir quién las ha dicho. De hecho, en el subtítulo el locutor reproductor revela que se trata de Franco Giordano, el secretario de Rifondazione Comunista, y que el referente espacial del sustantivo "isola" alude a Cerdeña, ya que el periódico se edita en esa isla italiana. La expresión entrecomillada, la cita, queda pues aislada de su marco.

El entrecomillado con frecuencia aparece antes del sujeto enunciador del mismo. Sin embargo, para que no pierda su efectividad, la cita debe ser atribuida inmediatamente. Por el contrario, se obtiene el efecto opuesto cuando la frase es larga y genérica y sobre todo si tras varias líneas se descubre que el autor de dicha afirmación es un personaje sin autoridad, por ejemplo un funcionario que enumera algunas medidas. Veamos algunos ejemplos en los que el entrecomillado logra el efecto deseado:

(4) "Non ho mai detto che lascerò il mio posto" precisa il Governatore Soru. (L'Unione Sarda, 15- 03-08, 7)

(5) "Boicottare la Cina? Si può". Sarkozy non esclude di disertare l'apertura dei Giochi. (Corriere della Sera, 26-03-08, 6)

(6) "Nos hemos presentado sin alianzas, corriendo un riesgo, para hacer un favor a la democracia”, explicó ayer Veltroni en su cierre de campaña. (El Mundo, 1304-2008, 5) 
Lo que parece ser una convención periodística por la que se estipula que las comillas son sinónimo de autenticidad logra casi siempre el efecto buscado en el lector; hacer más fiable la cita. El lector cree a pies juntillas que las palabras encerradas por el entrecomillado, son las de la persona citada, sin necesidad de cotejar la veracidad de dicha cita. No advierte la mano del periodista que previamente ha seleccionado una parte del discurso general. Se potencia, por lo tanto, el efecto de contacto directo con el protagonista real de la noticia convenciéndolo de la literalidad del texto citado.

(7) Zapatero se despidió con la expresión de un presentimiento: "Este mitin sé que me va a llevar a la victoria. Nunca lo olvidaré". (El País, 07-03-08, 18)

Por otro lado la presencia de fuentes oficiales de las que procede la noticia atiende también a criterios periodísticos: son fáciles de ubicar y manifiestan un enorme interés en que su punto de vista e ideología sean divulgados. Deben respetar un requisito mínimo, ser autorizadas para poder respaldar la información, como reflejamos a continuación en los fragmentos subrayados:

(8) "Ha vinto perché é stato il miglior stratega e dunque il miglior politico. Deve ancora dimostrare, però, di essere il miglior statista". Questo giudizio, magari un po'aspro di un portavoce dell'opposizione definisce però il dilemma in cui si trova José Luis Rodríguez Zapatero dopo la rielezione. (Il Giornale, 11-03$08,13)$

(9) "No lo hubiera consentido pero, además nadie se hubiera atrevido", señalan fuentes próximas al presidente. (El País, 20-04-08, 6)

El empleo abusivo, redundante e impropio de las comillas, ha ido modificando su valor de reproducción literal para asumir en su lugar el papel que desempeña en la oralidad. Se convierte pues en una señal de distanciamiento e incluso de escepticismo enunciativo por parte del locutor. Algo que suele darse con más frecuencia en los titulares italianos construidos de forma bimembre, en los que se reconoce desde el primer momento el responsable del discurso seguido inmediatamente de sus declaraciones, sin la mediación de ningún verba dicendi. ${ }^{4}$

Veamos algunos ejemplos:

(10) I vescovi: "Vade retro, Zapatero". (La Repubblica, 12-03-08, 3)

En (10) el periodista no pretende hacer creer al lector que los obispos hayan dicho realmente lo que se acota entre comillas. En realidad lo que él pretende es resaltar que está citando palabras que corresponden a ideas ajenas, no propias. De hecho, parece integrar en el discurso de los obispos los ecos, las palabras que

4 Cfr. Alarcos Llorach (1977: 140-142) 
fueron proferidas por otros, en otro contexto, reinterpretándolas y ajustándolas a sus propias necesidades argumentativas. Esto es lo que sucede, de forma natural en la oralidad, con las citas entrecomilladas.

Otra característica del periodismo italiano digna de ser señalada es el uso masivo de frases nominales en los titulares construidos mediantes citas directas bimembres. Este tipo de estructura se emplea abundantemente en la prensa italiana, sobre todo, debido a sus rasgos de brevedad, condensación o incisividad, que la convierten en una estructura apta en contextos muy variados al resultar fácilmente inteligible. Responde al criterio de la economía en la escritura periodística, al concentrar mucha información en enunciados de poca extensión.

(11) Cassini: "Opposizione costruttiva”. (La Nuova Sardegna, 15-04-08, 8)

En (11) cualquier italiano que sepa que Cassini es el líder del partido centrista Udc (Unione di centro) puede inferir el verbo "faremmo" (haremos) empleado para comprometerse a hacer algo en el futuro.

Los titulares explotan sobremanera este estilo de reproducción para adornar los hechos, dramatizar las noticias, para hacer sobresalir a los personajes, dando la impresión de cercanía, como si el lector asistiera al acontecimiento en vivo y en directo. El objetivo manifiesto es lograr la mímesis de un acto de habla. Para ello, sobre todo en Italia, se imita a menudo la organización de una entrevista televisiva y la opinión expresada por algún protagonista de la sociedad o de la política "inmediatamente" después de que haya ocurrido el suceso.

(12) Prodi volta pagina "Politica italiana addio"/ Bondi: Ingiusto abbandonarlo. Ti dedico una poesia. (Corriere della Sera, 10-03-08, 10)

En (12) aparecen dos sujetos enunciadores: Romano Prodi, por aquel entonces, aún Presidente del Gobierno (Presidente del Consiglio) y Sandro Bondi, diputado del PdL (Partito delle Libertà). Aunque no se realizara un encuentro físico entre ambos, la magia del periódico los reúne en un diálogo ficticio que se desarrolla en el titular y subtitular de una noticia. En ella Prodi parece despedirse de una personificada Política Italiana y Bondi, desde el subtítulo, parece escuchar sus palabras, comentando a un auditorio anónimo - como indica el pronombre complemento directo en posición enclítica abbandonarlo- que no sería correcto en ese momento tan duro para un político, abandonar la carrera profesional, después de tantos años en la política. Lo peculiar es que en la segunda parte de su enunciado el sistema deíctico se traslada a Prodi, que se convierte así en el alocutario de Bondi - Ti dedico - como indica el pronombre complemento de segunda persona singular. Este recurso teatral se engloba en el abanico de estrategias encaminadas a capturar la atención del lector.

Cabe subrayar, como se observa en (11), que las comillas no siempre son índice de literalidad o de fidelidad de la cita. Parecería extraño, si no, que Prodi 
dialogara con la Política Italiana, como si de una persona se tratara y se despidiera de ella en una alocución como la anterior. Parece más bien una interpretación de su pensamiento, comunicado para sus adentros y trasladado a la forma escrita para aderezar la noticia con tintes efectistas. Por consiguiente es más razonable pensar que lo que el periodista ha recogido es el sentido del discurso, sin modificarlo. De hecho, en el cuerpo de la noticia se refieren las palabras textuales de Prodi "Ho chiuso con la política", esta vez sin personificación.

Además de transmitir una mayor implicación emotiva, el DD es también un medio que se contagia de las formas y estrategias del discurso oral y del registro coloquial. Un claro ejemplo de ello es la habitual comparecencia de los marcadores argumentativos, tanto conectores como operadores discursivos, en los titulares de prensa, sobre todo los italianos. El periodista se vale de dichas herramientas lingüístico-pragmáticas para argumentar y plasmar los diferentes puntos de vista de los enunciadores que enlazan sus propios discursos con otros anteriores o como respuesta a los de otra persona, para poner de relieve el acuerdo o el desacuerdo a través de conectores coorientados o antiorientados, para justificar una determinada postura, para expresar la concesión-oposición, para atenuar o intensificar los efectos de un enunciado, etc.

Siguiendo a Antonio Briz, dichos marcadores no sólo ordenan la materia discursiva, también son "instrucciones de la actividad argumentativa (intención), guías para la interpretación”. (Briz, 2001:112) Ello explica por qué muchos titulares italianos comienzan con la conjunción copulativa $e$ con valor aditivo o la adversativa $m a$ con valor contra-argumentativo. Ambos introducen un enunciado haciendo referencia implícitamente a un "antes" que el lector conoce, o se presupone que conoce:

(13) Navarro-Valls: "Ma Zapatero ora abbandoni l'ideologia." (Corriere della Sera, $10-03-08,5)$

En la cita del que fuera portavoz del Papa Juan Pablo II durante más de 20 años, se aprecia una nota de resignación ante el resultado electoral en España, se asume por tanto que su postura acerca de la política de Zapatero en materia ideológica, es contraria. Se trata de una reacción de contrariedad velada ante la victoria de Zapatero, transmitida a través del conector discursivo "Ma". El periodista parece así dar por descontado que el lector comparte una serie de conocimientos previos sobre la difícil relación que han mantenido la Santa Sede y el ejecutivo socialista español desde su llegada al gobierno en 2004.

También las frecuentes fórmulas interrogativas pseudo-retóricas con respuesta instantánea que aparecen en los titulares han de ser englobadas entre los mecanismos pragmático-textuales que introducen un argumento relacionándolo con otros textos y situaciones anteriores.

(14) I miti di Veltroni? "A corrente alternata." (Il Giornale, 11-03-08, 7) 
El "nuevo" argumento puede apuntar a otros artículos aparecidos dentro del mismo periódico y/o de la competencia, o bien remitir a un saber compartido por el lector. Son afirmaciones o negaciones de algo que el lector conoce - $\mathrm{O}$ debería conocer- de antemano, que suelen desarrollarse en el cuerpo del artículo. Así hallamos enunciados como los siguientes:

(15) Berlusconi: "Contro la precarietà? Sposare mio figlio o un millonario." ( $L a$ Repubblica, 13-03-08)

Así, la original salida de Berlusconi en (15) ante la dramática pregunta de una joven sobre cómo solucionar la precariedad laboral y resolver los problemas que conlleva el desempleo, queda plasmada e intensificada en la pregunta retórica de Berlusconi y en su inmediata respuesta. El enunciador no pide realmente información a su interlocutor; en su interior está ya implícita la respuesta que se refuerza en la frase de infinitivo siguiente, con la que se fusiona como si de un único enunciado se tratara. La rapidez de la respuesta en este diálogo unidireccional da la sensación de firmeza y veracidad del contenido, sin posibilidad de réplica.

Pasemos ahora a analizar el Discurso Indirecto (a partir de ahora DI). El DI se diferencia del DD en primer lugar por su forma de presentación; se trata siempre de una reconstrucción aproximada, un resumen, a menudo cargado de los matices que aporta la elección de un determinado léxico por parte del locutor reproductor; en definitiva hay que entenderlo como una versión del discurso de otro locutor primario.

Como resume Graciela Reyes "Las oraciones que tienen una cita indirecta están formadas por un verbo de comunicación verbal y una subordinada sustantiva, encabezada por la conjunción que.${ }^{5}$ En el DI el periodista cuida más el contenido del enunciado que la forma en que fue pronunciado. Podríamos añadir que si en el DD el locutor reproductor realiza una especie de aseveración que bien podría formularse como "X dijo textualmente Y", con el DI, en cambio, la aseveración es más velada y correspondería más bien a una frase del tipo "Así doy cuenta de lo que $\mathrm{X}$ dijo".

En esta modalidad reproductora de discursos se asiste a una recontextualización del enunciado original que se ejecuta en primera instancia gracias a los elementos introductorios, el marco, que a su vez cuenta con señales demarcativas - entre las que se incluiría el verbo de comunicación y la mención al locutor del discurso original-y los indicios externos que aluden a las circunstancias que rodearon la situación enunciativa originaria ${ }^{6}$ y el modo en que fue proferida. Éstos últimos contribuyen a recrear y delimitar la escena y sobre todo la actitud

5 Reyes (2002: 31)

6 Así estructura Elena Méndez, siguiendo a J. L. Girón, los elementos que forman parte del marco. Méndez (1999:108). 
enunciativa de los diferentes locutores que participaron en dicho discurso. Ello explica, entre otras cosas, por qué en dicha función los adjetivos, juegan un papel fundamental, ya que transmiten los estados de ánimo y las intenciones de los locutores, si bien no despejan totalmente la duda de quién es el verdadero emisor, el locutor o el periodista. Así lo podemos comprobar en el recurso al adjetivo indecisa en (16), donde la cursiva remite una voluntad desacreditadora de Gallardón hacia Esperanza Aguirre, con la que parece concordar también el sujeto reproductor, hasta el punto de desdibujar los límites entre uno y otro.

(16) Gallardón dice que si la indecisa Aguirre quiere presentarse tiene "derecho" pero no apoyos. (El Pais, 10-04-08, 6)

Como vemos en (16) el locutor puede convocar la presencia de un enunciador político con cuyo punto de vista parece identificarse. Aun así, el proceso de identificación no se ha de atribuir solamente al modo de reproducción elegido. En la mayoría de los casos el periodista se vale del estilo indirecto como medio para introducir el punto de vista de los políticos. Es evidente que de ello no puede deducirse que cualquier locutor que maneje este tipo de construcción se identifique forzosamente con el punto de vista reproducido.

Es de sobra conocido que cualquier enunciado puede reflejarse con intenciones, fuerzas ilocutivas diferentes. De esta manera el marco permite indicar el acto lingǘstico original en el que se ha producido el enunciado o el proceso cognitivo que ha llevado a la verbalización de una idea o de una sensación. En el DI el sujeto reproductor puede decidir mantenerse fiel a lo que efectivamente se dijo, pero al mismo tiempo seleccionar el modo en el que se realizó dicho enunciado. Por esa razón, la elección del verbo introductor es de vital importancia y se convierte en una de las herramientas más eficaces para detectar la presencia y orientación del sujeto reproductor en el texto citado.

(17) Manu Chao denunciará al PP por utilizar una de sus canciones sin permiso. (El País, 02-03-08, 14)

Así en (17) el verbo denunciar informa acerca de un acto ilegal y aporta una valoración negativa del sujeto destinatario de la denuncia, el PP. Suele además ser habitual que la línea editorial del periódico que publica la noticia coincida ideológicamente con el sujeto que hace la declaración, tal y como sucede en este caso. $^{7}$

Como estamos observando la elección de un determinado verbo introductor le permite al locutor no sólo informar de lo que se ha dicho, sino también interpretar la voluntad que esconden las declaraciones:

7 Tendencialmente socialdemócrata, El País ha sido acusado abiertamente por el entorno del Partido Popular de apoyar los intereses del PSOE. 
(18) Aguirre rechaza "cambios radicales" y Rajoy insta a "amoldarse a la realidad" (El Mundo, 28-04-08, 1)

En el ejemplo anterior el verbo rechazar apunta a una resistencia de Esperanza Aguirre a aceptar algo que se ha expresado con anterioridad - en este caso se deduce la necesidad de cambios radicales - sin admitir propuestas en ese sentido. No sabemos a ciencia cierta de dónde proviene esa propuesta pero la oración copulativa que sigue y sobre todo el verbo instar atribuido a Rajoy hacen suponer que viene de éste último. El verbo instar permite interpretar así, las palabras de Rajoy no sólo como un acto enunciativo sino que además resalta en contraste con Esperanza Aguirre- la convicción del mismo en la necesidad de afrontar cambios dentro de su partido, por lo que pide a los militantes del PP que se ajusten a la realidad, de ahí que la petición encubra una crítica directa a las palabras de Aguirre y la forma en que ésta se realiza.

(19) Zapatero elude hablar de mayoría absoluta y confía en un triunfo "menos ajustado" (El País, 05-03-2008, 1)

La identificación de la intención ilocutiva por parte del lector es esencial para discernir el sentido que subyace a un enunciado. De ahí que en (19) el verbo eludir, no sólo nos informa de que no se produce ningún acto de enunciación —no hay palabras que reproducir - sino que se carga de matices negativos, en cuanto el lector sobreentiende que Zapatero evita un argumento espinoso pero de extrema importancia como es la posibilidad de no tener mayoría absoluta en las elecciones.

Ello demuestra que cuanto más permeable a connotaciones es un verbo, más abierto a interpretaciones y valoraciones quedará el discurso por parte del periodista. Veámoslo a continuación en un ejemplo italiano:

(20) Il leader del Partido Popular ha di nuovo attaccato il premier socialista uscente, accusandolo fra l'altro anche in questo dibattito di avere mentito al paese nella vicenda della trattativa avviata con l'Eta due anni fa, e lo ha invitato a "chiedere scusa agli spagnoli”. (La Repubblica, 04-03-08, 4)

Por su parte en (20) la elección los verbos atacar y acusar para reproducir la cita de Rajoy, tiñe de matices negativos la figura de Zapatero "il premier socialista uscente", señalado como la persona responsable de haber negociado con E.T.A. y haberlo mantenido oculto a los españoles. Al optar por estos verbos el periodista hace partícipe al lector de la veracidad de la acción que se condena. Algo que confirma también el enorme hincapié que hace Rajoy sobre dichas negociaciones, como reflejan los sintagmas "di nuovo", "fra l'altro" y "anche in questo dibattito", una actuación que el líder del PP vuelve a sacar a colación por el rechazo unánime que éstas suscitan entre los españoles. 
Directamente relacionado con la fidelidad de la reproducción, se establece una distinción entre la lectura de re y la referencia de dicto. La primera, propia del DI, se caracteriza como señala Graciela Reyes porque en ella "las expresiones referenciales se interpretan dando prioridad a su contenido", frente a la lectura de dicto, correspondiente al estilo directo, en la que "la responsabilidad de la expresión (y con ella del punto de vista, valoración, etc.) se atribuye al hablante citado". ${ }^{8}$ De ahí que la operación de interpretación se haga inevitable cuando hay que referir un discurso que contiene expresiones lingüísticas ambiguas o comprensibles solo a la luz de un determinado contexto.

Además, para que una cita sea eficaz resulta indispensable que el marco contenga información sobre las circunstancias que rodean la enunciación. El dónde, el cómo, y el cuándo no son menos importantes que el qué se dice. La cita es más efectiva cuanto más completo es el marco, que entonces nos prepara a captar todos los matices de la situación que envuelven al sujeto que está a punto de hablar. Veamos el siguiente ejemplo:

(21) Il primo messaggio dall' amministrazione Usa era arrivato già nella serata di lunedì, a risultato acquisito. Ieri invece la telefonata personale di George W. Bush che ha fatto a Berlusconi le sue congratulazioni e si è detto pronto a lavorare di nuovo con lui. (Corriere della Sera, 16-04-08, 2)

En (21) contamos con referencias precisas del momento en que se produce el acto de habla - "ieri" - , del medio en que se realiza - "la telefonata"- y de quién es el sujeto - "George W. Bush"- que llama a Berlusconi. Pero el cronista va más allá y da detalles como el carácter "personale" de la llamada, algo que pone de manifiesto la estrecha sintonía que existe entre ambos jefes de Gobierno, tal y como corrobora el hecho de que la Administración Bush llame dos veces para felicitar a Berlusconi y, sobre todo, enfatiza el fragmento "pronto a lavorare di nuovo con lui".

Por otra parte, el DI le permite al locutor reproductor una mayor libertad de actuación, ya que al no estar vinculado a límites formales, sino de correferencialidad, puede añadir información basada en su propio punto de vista dando pie a ambigüedades, porque la elección de un determinado término puede incluir valoraciones acerca del discurso del emisor original. Así, en (22), la cursiva de inaccettabile desorienta al lector que no es capaz de distinguir claramente si el único próposito es el de citar textualmente una palabra empleada por Veltroni, o también la de enfatizar, por algún motivo, el término en cuestión:

(22) Veltroni dichiarò mercoledì sera di non volere andare a rispondere ai giornalisti perché si trattava di una vicenda inaccettabile. (Il Sardegna, 28-03-08,11)

8 Reyes (2002: 20) 
No tenemos las palabras textuales de Veltroni pero las "oímos", podríamos reconstruirlas, si bien, nunca literalmente, puesto que toda cita, hasta la más literal, nunca es idéntica a las originales. El periodista interpreta gracias al DI las palabras ajenas dándole prioridad al contenido sobre la forma en que fueron pronunciadas y altera las coordinadas deícticas. En la reformulación que se opera no sólo se modifican las marcas pronominales sino también los tiempos verbales. Lo que era presente para Veltroni se transforma en pretéritos indefinidos (dichiarò, precisò) puesto que en la estructura espacial lo que sería el momento presente "hoy" del emisor originario, Veltroni, se vuelve "mercoledì sera" para el sujeto que refiere.

Como acabamos de observar, el sujeto reproductor del DI se hace cargo de todos los reajustes gramaticales-léxicos y referenciales que se hayan de realizar, intentando reconstruir la información originaria, porque quien cita la adapta a una nueva situación comunicativa; la propia. El sistema de los deícticos de persona, espacio y tiempo muestran claramente esa diferencia. Así pues, si desde los parámetros de la gramática en el DD el centro deíctico se mantiene intacto y el paradigma deíctico original gira alrededor del sujeto que pronuncia las palabras, en el DI ese centro se traslada al sujeto que reproduce, el locutor citante.

Eso no es todo; al tratarse de una reformulación el periodista resume las palabras del enunciado originario por razones de economía verbal en numerosas ocasiones. Se establece entonces una jerarquía entre las partes del discurso; algunas se profundizarán y se expondrán con todo lujo de detalles, mientras que otras, las que no interesan por varios motivos, simplemente quedarán relegadas al anonimato. De ahí que se critique la falta de objetividad e imparcialidad del texto periodístico.

Los ejemplos reseñados en DD y DI demuestran que el texto periodístico se convierte en un complejo entramado de citas directas e indirectas que se van alternando unas tras otras para motivar el interés del lector. Si el DI sirve para introducir información nueva, al ofrecer elementos de comprensión en el marco introductorio y dar espacio a las opiniones, está asimismo probada la eficacia del DD para concluir, aclarar o corroborar la información al tiempo que aporta color local. En el DI el periodista se aleja a menudo de las palabras literales del locutor real, puesto que elige de forma intencional el verbo que aparecerá en el artículo. Y es precisamente en esta operación en la que puede introducir su subjetividad, proponiendo una imagen más o menos atractiva de acuerdo con su proximidad ideológica al periódico en cuestión.

\subsection{Las citas mixtas}

En los textos periodísticos, y no sólo en ellos, existen otras formas híbridas de reproducción discursiva, que mezclan la estructura clásica del DD y del DI. Algunos estudiosos denominan estas manifestaciones heterogéneas, tan recurrente en las estructuras periodísticas, cita mixta directa e indirecta. En este 
procedimiento se combinan el DD y el DI en un mismo enunciado, intercalando fragmentos discursivos literales, sin que la cita completa pueda calificarse en rigor como DD. Entre este tipo de citas se incluiría el DD subordinado (Méndez, 1999) que adopta la forma introductora del DI como las señales demarcativas (sintaxis subordinada) para revestirse del ropaje tradicional de la cita en DD. Así, hacen acto de presencia las comillas a la vez que los rasgos distintivos de reproducción señalan al locutor original.

(23) Il leader del Partito delle libertà affermò ieri in tono trionfale che "Se io decido oggi di dare vita ad un'iniziativa imprenditoriale, alla fine ci riesco". ( $\mathrm{La}$ Repubblica, 26-03-08, 3)

En (23) el marco parece anunciar un DI: el verbo dicendi introduce un acto expositivo para poner de manifiesto el modo de encajar en el argumento del que se está hablando y el uso del nexo "che" que predispone a una oración subordinada. Sin embargo, la deíxis pronominal que apunta a una primera persona singular "io, decido, ci riesco" y espacial actualizador "oggi" se refieren no a la persona que reproduce - el periodista - ni tampoco al momento de la reproducción, puesto que ese oggi no es el hoy del periodista sino el día anterior, como corrobora el "ieri" que aparece en el marco. Los indicios internos inscriben pues ese discurso en boca de Berlusconi y en su momento presente.

Al señalar que las palabras entre comillas no son suyas el periodista puede marcar tanto deferencia como distanciamiento o escepticismo con respecto a las palabras del otro. En este tipo de citas, en los que DI y DD se alternan sin solución de continuidad la responsabilidad del periodista aumenta proporcionalmente cuanto mayor sea la presencia del DI. Al insertarse el texto entrecomillado en un DI se complica significativamente para el lector la labor de reconstrucción de las declaraciones originales y resulta más difícil distinguirlas de las connotaciones que el periodista ha aportado consciente o inconscientemente con su intervención:

(24) Paralelamente, Berlusconi anunció, en un mitin de su formación celebrado en Nápoles, que si gana las elecciones sus primeros consejos de ministros tomarán medidas "duras e impopulares" y prometió acabar con la crisis de las basuras. (El Mundo, 04-04-08, 2)

La extensión de la cita en DD puede oscilar: encontramos citas directas englobadas en DI que van desde una simple palabra que se considera sintetizadora o emblemática del discurso citado, pasando por un sintagma nominal, hasta llegar a frases de dimensión considerable. Su presencia en el periodismo escrito es muy superior a la del resto de formas de reproducir el discurso ajeno, gracias a las posibilidades de distinguirlo que ofrecen los signos gráficos como las comillas o las negritas o las cursivas. La incursión de citas directas dentro del DI 
prolifera en los textos periodísticos, dado que da realce expresivo al privilegiar algunos tonos y al mismo tiempo genera una impresión de literalidad pues reproduce determinadas expresiones de forma textual. Veamos algunos ejemplos:

(25) La insinuación por parte de Aguirre de que la socialdemocracia se sentía "cómoda" con Rajoy mientras ella está identificada con el liberalismo le llevó a una defensa cerrada de lo público, algo típico de los socialdemócratas pero también de los democristianos. (El País, 20-04-08, 10)

Con el DD las palabras ajenas se citan, mientras que con el DI se "traducen" y lo hace un locutor que actúa como intermediario entre la fuente original y el lector. El periodista recurre a la fórmula de enlace introductor en DI y, a continuación, se recoge el fragmento citado en referencia de dicto. Así se desvincula de la responsabilidad que supondrían tales afirmaciones:

(26) Según Arenas, él logró “desmontar" los argumentos de Chaves y demostrar que "merece la pena un cambio" en Andalucía. El candidato popular defendió su decisión de sacar a relucir el patrimonio de su adversario, porque, a su juicio, es un asunto que interesa a la opinión pública. Arenas lamentó que Chaves se lo haya tomado "como una cuestión personal". (El País, 03-03-08, 4)

El locutor reproductor da la palabra a la voz enunciadora en los puntos más significativos de su discurso, porque así dota tanto al marco, como a la cita, de una mayor autenticidad. De esta manera la responsabilidad del enunciador primario se acota a los segmentos entrecomillados, que suelen ser los que generan mayores reacciones en el lector. No obstante hay que precisar que la responsabilidad del periodista no queda resguardada en los casos en los que no resulta fácil delinear de forma objetiva las declaraciones iniciales de los enunciadores primarios y distinguirlas de todos esos matices que el periodista incluye en su reformulación. En todo caso se dará más cabida a las posibilidades de interpretación cuanto más extensa sea la parte dedicada al DI en el texto. Veámoslo en el siguiente ejemplo, donde se hablaba de la posible sucesión de Mariano Rajoy, como cabeza del Partido Popular, tras los resultados, poco alentadores, de las últimas elecciones generales celebradas en España.

(27) Tras ello, en rueda de prensa, Rajoy no quiso dar muchos detalles sobre sus próximos pasos más allá de la convocatoria del congreso nacional. El líder del PP reclamó "tomarse sus propios tiempos" para "preparar el terreno para ganar las próximas elecciones" generales y aseguró que no iba a despejar las caras de su equipo "hasta el día anterior al que se celebre la votación". [...] (El País, 11-03-08, 12)

Notamos además que el locutor reproductor da y quita la palabra a Rajoy, el enunciador primario, sin seguir —al menos aparentemente- ningún criterio 
en concreto. Llama la atención el primer fragmento entrecomillado "tomarse sus propios tiempos" porque las referencias deícticas, representadas con el posesivo de tercera persona singular "sus" no parecen ser las palabras literales de Rajoy, puesto que se esperaría encontrar uno de primera persona singular "mis". Por consiguiente, es razonable pensar que se trata de las palabras del periodista puestas en boca de Rajoy.

(28) Il leader di Rifondazione Giordano rilancia la campagna elettorale da Carbonia. Nel mirino Pd, Pdl e "l'americanizzazione della politica". (L'Unione Sarda, 08-04-08, 5)

Las palabras que aparecen entre comillas pertenecen a la voz originaria, en este caso del líder de Rifondazione Comunista, Franco Giordano. El sintagma "l'americanizzazione della politica" es una parte de su discurso y las comillas una marca textual que evitan una posible confusión entre el sujeto enunciador Giordano- y el sujeto reproductor - el periodista - que de esta manera se distancia de lo que dice Giordano y delimita su responsabilidad enunciativa.

En general, el periodista debería transmitir los hechos al lector sin que se note su presencia, su voz; sólo así crece su nivel de credibilidad y seriedad. Esta capacidad de "desaparecer", de hacerse "invisible" requiere gran maestría, que se pone de manifiesto sobre todo en el uso de las comillas y en la elección de las palabras referidas, precisamente porque las dice otra persona. Pero la mayoría de los diarios no hacen gala de dicha neutralidad, de ahí que el periodista a menudo seleccione los fragmentos más significativos en función de sus propias necesidades discursivas, sin anunciar una cita en DD como tal. Lo veremos en el siguiente fragmento del periódico Il Giornale. Este diario es, de entre todos los que existen en Italia el que mejor pone de manifiesto que la frontera entre la información y la opinión es decididamente ilusoria. ${ }^{9} \mathrm{E}$ l segmento seleccionado como discurso directo es un sintagma nominal "vento nuovo" que pertenece al discurso de Walter Veltroni, líder del "centro izquierda" italiano y adversario político de Berlusconi en las últimas elecciones generales italianas. Con él se refiere a los resultados de las últimas elecciones generales españolas y francesas que dieron la victoria a los socialistas en ambos países:

(29) Scambiare i propri desideri per la realtà. È quello che ha fatto Veltroni quando, commentando i risultati delle elezioni in Spagna e in Francia, ha parlato di "vento nuovo", cioè di un'Europa che riprende ad andare a sinistra. (Il Giornale, 11-03-08, 1)

9 De propiedad de Berlusconi, desde 1978, es un periódico declaradamente de derechas que da amplio espacio a la política y lo hace ofreciendo valoraciones conformes con la ideología política que representa. 
La posición del locutor reproductor en este contexto se explicita, como vemos, desde el principio del artículo, a través de la frase de infinitivo inicial "Confundir los deseos con la realidad" desde donde se preanuncia a la persona de la que se va a hablar, Veltroni, caracterizado de esta manera como un ingenuo, algo que corrobora la frase: "Es lo que ha hecho Veltroni". El sintagma "vento nuovo" adquiere una nueva valencia en la reproducción del periodista: si para Veltroni era símbolo de transformación, de optimismo y esperanza en el cambio político, como se puede observar en el resto del artículo, para el periodista de Il Giornale se tiñe de connotaciones irónicas y negativas. Notamos entonces que la repetición del sintagma "vento nuovo" se convierte en un eco que deforma el sentido del enunciado original y responde a una intención implícita de burla e ironía por parte del periodista.

Existen, como vemos, estrategias discursivas eficaces, como la ironía, para mantener durante la lectura el significado abierto, polisémico, permitiendo al lector entrar en el juego de la interlocución. Los periodistas son conscientes de que el público selecciona las noticias en función de lo que quiere leer y por eso en la línea de la estrategia de la complicidad, se busca una relación directa con el lector, que se convierte en una especie de co-enunciador del texto. Esta categoría profesional sabe que el verdadero poder de persuasión no reside tanto en la manifestación de su opinión, como en la transmisión al lector de una determinada visión de la realidad.

\subsection{El Discurso Indirecto Libre}

Si bien el predominio de la cita mixta como mecanismo de reproducción de discursos ajenos es indiscutible en los textos periodísticos, ello no impide que también se asomen a esta escritura otros procedimientos como el Discurso Indirecto Libre (DIL). Es más, el DIL habría de ser estudiado en realidad como una forma de cita mixta porque en él vuelven a confluir tanto el DD como el DI. A través de esta modalidad de discurso que se genera a partir del DI con omisión de los verbos introductores y nexos, el narrador expresa el contenido del enunciado de un personaje —además de sus pensamientos, ideas, sensaciones, etc.- manteniendo el estilo y léxico propios de éste último. Ello da pie al entrecruzamiento de las voces del narrador y el personaje y por consiguiente a una ambigüedad discursiva que dificulta la distinción de los discursos que pronuncia cada uno por separado.

En los textos periodísticos el DIL se puede definir como discurso vivido por alguien en función de reflejo, en el que el periodista intenta borrar su presencia, generando una narración que parece dejarse llevar sin que nadie la dirija, para transmitir neutralidad. El periodista se cala en lo que piensa el enunciador, se mete en su piel, utilizando su voz y su lengua para expresar pensamientos, contar acciones y acontecimientos. Esta ambigüedad comunicativa inherente al DIL provoca que el lector no pueda saber con seguridad si lo que el periodista 
señala es responsabilidad suya o si se trata de la representación de un punto de vista ajeno, algo especialmente habitual cuando se reproduce el enunciado de algún político. El periodista adopta, sin declararlo, las palabras y, por extensión, el punto de vista del político. Un caso evidente es la presentación de Berlusconi como amigo personal de los potentes del mundo. Así, hallamos fragmentos como:

(30) Bush invita al suo ranch all'amico Berlusconi. (Il Giornale, 11-03-08, 5)

(31) [...]In un recente incontro nell'Isola con l'amico Vladimir Putin, Berlusconi ha sottolineato la necessità di "un cambiamento radicale nella gestione delle risorse energetiche”. (L'Unione, 22-04-08, 4)

Esta característica voz locutora reproductora del periodismo italiano, que parece una esponja en lugar de un sujeto independiente, favorece la presencia del DIL.

Analicemos más detalladamente la siguiente secuencia:

(32) $[\ldots]$ «Ditemi voi... Ditemi voi come c... faccio a portare avanti una trattativa quando quella che dovrebbe essere la mia testa d'ariete è ridotta così!». Sono passate le quattro di mattina quando al quinto piano di via dell'Umiltà Carlo Giovanardi mostra al cosiddetto «tavolo dei sette» il display del suo cellulare che ha appena immortalato Emerenzio Barbieri, gomiti sul tavolo e testa pencolante tra le mani. L'ex deputato dell'UdC, infatti, se la dorme beatamente mentre gli altri continuano a discutere di posti in lista e candidature sicure. $\mathrm{Su}$, sveglia! Sonno profondo, se neanche le urla divertite di Giovanardi e lo sghignazzare dei presenti riesce nell'impresa di ridestarlo...... (Il Giornale, 11-03$08,4)$

El texto presenta una heterogeneidad de estilos de reproducción que van desde el DD de la primera frase entrecomillada, atribuida a Carlo Giovanardi, pasando por una cita no expresa, es decir, no atribuible a ninguno de los enunciadores del discurso, "tavolo dei sette", "sonno profondo", llegando a recurrir a resúmenes narrativos "mentre gli altri continuano a discutere di posti in lista e candidature sicure", "se neanche le urla divertite di Giovanardi e lo sghignazzare dei presenti riesce nell'impresa di ridestarlo" y se termina con una muestra de DIL "Su, sveglia!!" a los que habría que añadir los comentarios valorativos del periodista, "Infatti". Esta mezcolanza genera una ambigüedad porque los confines a quién atribuir lo que se dice están difuminados. ${ }^{10}$

Aquí se presentan, con diversas modalidades de atribución las posiciones de otros enunciadores. Por un lado tenemos al diputado del PdL (Partito delle

10 Graciela Reyes sintetiza "Las palabras ajenas, y con ellas los puntos de vista ajenos, quedan así infiltrados en el discurso del que las usa, dando lugar, a veces a ambigüedades o malentendidos." Reyes (2002: 44). 
Libertà) Carlo Giovanardi, emisor del enunciado exclamativo en DD. La exclamación retórica que imaginamos dirigida a sus alocutarios - los otros siete miembros de la mesa de negociaciones o "tavola dei sette" - refleja su peculiar modo de hablar, que encadena enunciados poco precisos, como si de asociaciones se tratara, con evidente descuido de la forma. Resulta un claro ejemplo de sintaxis oral teñida en este caso de un registro coloquial, como lo demuestran las repeticiones del sintagma "Ditemi voi" y la reducción u omisión por parte del periodista, de la palabrota "cazzo", insinuada mediante la inicial y los puntos suspensivos. Sin embargo, ello no dificulta la comunicación del sentido original que el lector reconoce fácilmente valiéndose de una implicatura conversacional. El resultado es un enunciado determinado por la improvisación formal en el que priman los valores exclusivamente comunicativos, tales como la fluidez y la expresión del sentido global subjetivo.

Parece más un servicio vídeo en el que el locutor reproductor intenta describir con rigor documental ("gomiti sul tavolo e testa pencolante tra le mani") la reunión de los 7 diputados del Pdl. Decimos intenta porque aparte de la precisión y la carga de objetividad que comunican los deícticos espaciales y temporales ("Sono passate le quattro di mattina quando al quinto piano di via dell'Umiltà"), los comentarios en su conjunto impregnan de sesgo subjetivo todo el discurso, que acaba imponiéndose sobre la pretendida objetividad: ("Infatti", "se la dorme beatamente", "le urla divertite").

En la actualidad, la información se valora más por su capacidad de enseñar los acontecimientos en desarrollo, a medida que se producen, convirtiéndose en una historia contada sobre la marcha. De hecho, nuestro locutor parece hallarse dentro de ese piso observando la escena y sus actos de habla, dando además rienda suelta a los pensamientos de los enunciadores. A este propósito es imposible discernir quién exclama la orden en imperativo Su, sveglia! ni quién añade el sintagma nominal Sonno profondo. ¿Es Giovanardi? ¿Son los otros diputados? ¿O es el locutor? Sólo podemos hacer conjeturas, llenando los vacíos propuestos y leer entre líneas, para darnos cuenta de que se trata del periodista con la voz prestada de Giovanardi y sus compañeros de partido.

En realidad resulta paradójico que esta modalidad de reproducción de discursos se emplee en el periodismo, puesto que el objetivo principal de esta técnica narrativa, en la que sin anunciarlo previamente el narrador abandona su voz y su visión y se adueña de las del personaje por un momento, es confundir a drede los planos de focalización, borrando todas las marcas que puedan identificar al narrador, algo que no casa bien con la esencia periodística que promulga una documentación de la realidad con objetividad notarial.

Consecuentemente, el periodista debería señalar de forma clara que está refiriendo las palabras de otros, porque las palabras son siempre portadoras de un determinado punto de vista y asumir ciertas palabras significa también aceptar las convicciones que éstas vehiculan. De lo que se deduce la siguiente ecuación: 
si el periodista asume las palabras de los enunciadores de los que habla, implícitamente se identifica con sus convicciones e ideas y las avala. Esta es una identificación que pasa subrepticiamente bajo la égida de la espontaneidad, viveza y rejuvenecimiento de la escritura periodística.

Las declaraciones de políticos llenan las páginas de los periódicos, son ellos mismos los que exigen ser entrevistados, citados, reproducidos. Si asumir la palabra ajena implica de alguna manera creer en ella, está claro que el objetivo del político se sustenta en el concepto de hablar para ser creído. La estrategia del político sigue unas directrices bien definidas, asentadas en la convicción de que hablar de forma asertiva y repetir hasta el hastío dicha afirmación conlleva, como resultado final, a la persuasión y autoconvencimiento del lector de que lo que dice el político es la verdad. Esta ecuación se sintetiza a la perfección en la siguiente viñeta. ${ }^{11}$

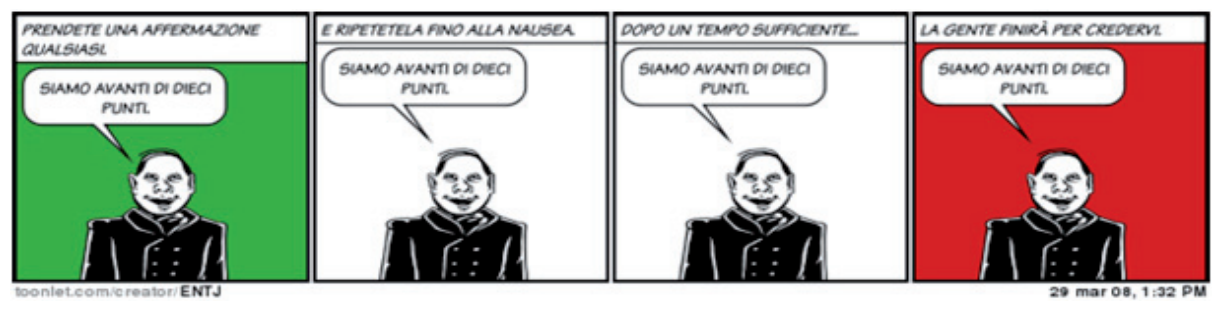

Cuando la voz del periodista deja de existir y se confunde — hasta fundirsecon la voz del sujeto, queda patente la gravedad de las consecuencias de dicha identificación en el caso hacer hablar a los políticos: la noticia sigue las palabras de la autoridad política. Y esto es lo que hoy en día sucede de manera sistemática en la prensa. El periodista renuncia a su función crítica y se limita a referir las declaraciones de los políticos, valiéndose de la "técnica del bocadillo" por la que se suceden las declaraciones del gobierno, de la oposición para volver a recoger las del gobierno.

Si el periodismo exige poder y quiere llevar a cabo su función de cuarto poder, debe prestar cuidado a no caer en errores de contaminación, distanciándose de las palabras (y puntos de vista) de quien ejerce esos poderes a los que hace de contrapeso. Sin embargo en España y aún más en Italia, el periodismo se apropia, sin declararlo, de las palabras y de los modos de decir del político, sin distanciarse y sin indicar que está reproduciendo palabras ajenas. Un ejemplo concreto en la prensa italiana es la costumbre generalizada de llamar "governatore" al presidente de una Región italiana;

11 Extraída del blog de Repubblica.it. Disponible en http://netmonitor.blogautore.repubblica. it/2008/03/31/porcellum-dubbi-e-borsettate-e-la-sindrome-del-rush-finale/ 
(33) Doccia fredda per il governatore, non sarà sul palco con Walter. «Non lo so, non ho ancora letto, perciò come è mio costume, per adesso non commento». Il governatore Antonio Bassolino liquida i giornalisti e s'infila nell'auto scuro in volto. (La Repubblica, $04-04-08,2$ )

Se trata de un término que introdujo el presidente de la región de Lombardía, Roberto Formigoni, y que a la postre ha sido adoptada por los periodistas italianos, si bien el cargo de gobernador no esté contemplado en el sistema de administración político italiano. Al adoptarlo el periodista se decanta por no señalar la contradicción, aceptando una visión política que prevé un cambio en dicha dirección. Consiste, al fin y al cabo, en una abdicación de la función crítica del periodismo.

\subsection{La cita no expresa}

En nuestro recorrido por los procedimientos de citas llegamos a una forma de atribución discursiva desprovista de marcas sintácticas tales como el verbo introductor o la referencia a la persona cuyo discurso se reproduce. Esta forma de reproducción se denomina cita no expresa.

Cuando conversamos en un registro coloquial solemos introducir relatos dramatizados que vivifican y actualizan una historia pasada, rasgo en estrecha relación con el carácter inmediato y actual de la conversación coloquial. Desde el punto de vista estrictamente discursivo, no cabe duda de que esos relatos favorecen la aparición del DD. Para aportar mayor autenticidad y colorismo a los relatos y, sobre todo, a esos protagonistas de la escena enunciativa, intentamos imitar lo más fielmente posible su modo de hablar. En la conversación coloquial incluimos dichos que proceden del saber común, expresiones idiomáticas, léxico argótico; repetimos sintagmas fijos basados en estereotipos, eslóganes, rutinas conversacionales, citas de libros, etc. y todo ello para respaldar una determinada. Asimismo, al referirnos a una persona intentamos emular las peculiaridades de su modo de hablar, las frases que pronuncia con más frecuencia, sus tics lingüísticos, sus vacilaciones, etc. Nuestro discurso se nutre así de las palabras de otros, transformando y dejándose transformar por las costumbres lingüísticas del sujeto enunciador originario y, por ende, de la variedad y del registro sociolingüístico en que dicho discurso fue pronunciado. El sujeto locutor intercala pues vocabulario, acento y valores propios de la persona citada, cuando la hay.

Todo ello, lo podemos aplicar al texto periodístico pues, en su afán por acercarse a la oralidad absorbe en su seno un número considerable de discursos sociales, manifestando así una acentuada polifonía en su "prosa". En sus enunciados el periodista conjuga las voces "visibles e invisibles" de diversos enunciadores, a través de mecanismos altamente especializados de discurso referido - como las citas no expresas- en las que el sujeto locutor no refiere tanto las palabras textuales de un discurso ajeno atribuible a un sujeto concreto sino que 
menciona un modo de hablar foráneo "sin alterar para nada su continuidad sintáctica, pero distanciándose de ese decir ajeno mediante otros recursos lingüísticos, no propiamente sintácticos, que tiene a su alcance: marcas tipográficas en lo escrito, cambios de entonación en lo hablado, remedos o imitaciones de modos de hablar o simplemente mediante la incorporación de variantes dialectales o sociolectales que no son propias del sujeto que habla." (Méndez, 1998: 142)

(34) Lunica cosa che non puoi fare è prenderti un panino al bar perchè, come dicono a Roma "costa na cifraaa!" (La Repubblica, 08-05-08, 12)

Notamos que el enunciado entrecomillado del fragmento anterior, no puede ser atribuido a una persona en concreto, sino al conjunto de los romanos, como indica la secuencia "come dicono a Roma". Pero el registro informal de la expresión romanesca "costa na cifraa!" se vincula a un grupo de usuarios de clase social baja y un estrato cultural popular, por lo tanto es un reflejo sociolectal. El alargamiento vocálico ha de analizarse como una marca suprasegmental que vehicula una actitud polémica por parte del enunciador ficticio. De hecho, el contexto en que aparece esta forma de cita implícita es el de la Feria del Libro de Turín que se celebraba por esas fechas y en la que, a tenor del enunciado, el único aspecto negativo de la organización era el precio excesivo de los bocadillos. El discurso romano le sirve al locutor para teñir su discurso de notas pintorescas y para mostrar una perspectiva diferente. Veamos otros ejemplos de citas no expresas:

(35) ¿Fue esa frase palmaria un último mensaje electoral?, ¿Iba dirigido a las familias? ¿Era una manera de asegurar los votos del sur, donde hacía sólo unos días los niños de un colegio napolitano aplaudieron en clase espontáneamente al oír el nombre de otro béroe, el mafioso más sanguinario de la historia de Italia, Totò Riina? Quizá todos preferimos, por pura higiene mental, quedarnos en la superficie, con el Berlusconi más cercano y bromista. [...]

Pero, como dijo el clásico, hay gente pa’tó. Y otros estadounidenses, en cambio, se rifan a Berlusconi. El propio Bush, por ejemplo, se ha congratulado de poder volver a trabajar con "ese gran aliado de América" - por suerte para el mundo no coincidirán por mucho tiempo-, y no ha tardado ni 24 horas en invitarle a cenar en la Casa Blanca. (El País, 20-04-08, 2)

La secuencia está extraída de un interesantísimo artículo de opinión dedicado a la vuelta de Berlusconi como Presidente del Consiglio. El periodista, Miguel Mora, siguiendo la línea editorial de El País, da una visión indiscutiblemente negativa de la figura de este empresario-político y denuncia abiertamente sus contactos con la mafia. De hecho, para el italiano medio la palabra familias, marcada en itálica, connota la forma de asociacionismo típica de todos los tipos de mafia (la siciliana, la camorra napolitana o la 'Ndrangheta calabresa). Estas "familias" tienen una estructura federativa, con afiliados que disponen de un carnet 
y que se rigen sólo por un peculiar sentido del honor. Resulta evidente, por lo tanto, que el periodista en la pregunta retórica “¿Iba dirigido a las familias?" se refiere implícitamente a un modo popular, difundido entre la sociedad italiana, de denominar metonímicamente a la mafia y del que nuestro periodista se distancia a través de la itálica.

Ahora bien, el hecho de que una palabra o grupos de palabras aparezcan marcadas tipográficamente no es siempre indicio de una cita no expresa. Así sucede con el término héroe. Si el periodista lo marca es para señalar su discrepancia con aquellos que realmente consideran como un héroe a una persona de la calaña de Totò Riina, un peligroso mafioso. Se distancia entonces de esos niños de Nápoles y sobre todo de Berlusconi, del que se dice en otro lugar del texto, que calificó de héroe al mafioso Vittorio Mangano ${ }^{12}$.

Notamos de nuevo una connotación autonímica en la secuencia "Pero, como dijo el clásico, hay gente pa'tó". Imita el modo de hablar de un sujeto indefinido, declarado en una paráfrasis, en cuyo enunciado se asiste a una relajación articulatoria que genera la pérdida de sonidos y que se podría adscribir a la esfera de la modalidad fonética del habla andaluza. En la paráfrasis citativa "como dijo el clásico" la argumentación se basa en el consenso general y la fuente de la "cita", el conjunto del saber popular que transforma la expresión hay gente pa'tó en una frase hecha, que la comunidad de hablantes puede aprovechar en función de sus necesidades argumentativas. Aquí el periodista la emplea para descalificar a los italianos que han votado a Silvio Berlusconi; esta frase aporta más fuerza ilocutiva al enunciado que si el periodista hiciera explícita la implicatura que recorre el fragmento: muchos italianos son tontos porque si no lo fueran no habrían votado a Berlusconi. ${ }^{13}$

La forma de heterogeneidad mostrada puede reducirse un sintagma nominal, a una interferencia léxica como vemos en los siguientes ejemplos:

(36) [...] Además (Rajoy) recordó que él lleva en el PP desde 1977 mientras ella (Aguirre) fue aceptada en 1989, cuando entró su Partido Liberal. Esto es, él, pata negra de Alianza Popular, como Alberto Ruiz Gallardón, José María Aznar o Rodrigo Rato, tiene mucho más pedigrí pepero. (El Pais, 20-04-08, 10)

El discurso de Rajoy se salpica de expresiones que probablemente nunca profirió, contaminado de metáforas gastronómicas de voces ajenas, no identificadas

12 [...] El último día de la campaña electoral, por ejemplo, tras haber calificado de "héroe" al difunto capo siciliano Vittorio Mangano, condenado tres veces por homicidio y narcotráfico a cadena perpetua, y que trabajó dos años, entre 1974 y 1976, en la villa milanesa del magnate (por eso se le conocía como el Guardés de Arcore), Berlusconi sostuvo, en directo, ante las cámaras de Tele 5, que Mangano, fallecido en 2000 bajo arresto domiciliario, nunca fue condenado en firme. [...] (El País, 20-04-08, 2)

13 Una idea por lo demás ya expresada en la cita directa de la escritora Erica Jong: "Berlusconi es un payaso como George W. Bush. No entiendo cómo los italianos le han votado. Lo mismo hubiera dado que eligieran a Tom Cruise o a Paris Hilton". (El País, 20-04-08, 2) 
que responden a clichés lingüísticos, a muletillas que los hablantes de una comunidad lingüística usan en determinadas ocasiones, para apoyar su tesis. De hecho en el registro coloquial, ser de pata negra, indica poseer cualidades de genuinidad, pureza y que son precisamente las que Mariano Rajoy se autoatribuye en su discurso para ensalzar - por contraste con Esperanza Aguirre- su autenticidad y prestigio dentro del Partido Popular.

Este mismo concepto vuelve a ser reiterado con el sintagma metafórico pedigrí pepero, con el que se pretente dejar constancia de que Mariano Rajoy tiene características propias y diferenciales de otros miembros del partido, en referencia implícita a Aguirre. A su vez el atributo pepero ha de ser entendido como una forma de denominación de los simpatizantes del Partido Popular, concebida desde la perspectiva de la izquierda española y por consiguiente, llena de connotaciones negativas. Así pues resultaría paradójico que Mariano Rajoy al hablar de su ascendencia política se autodefiniera tomando prestado un adjetivo forjado por la izquierda para desprestigiar a la derecha. No cabe la menor dudar de que la intención que anima al periodista de El País, al poner en boca de Rajoy dicho término despectivo, más propio de la jerga izquierdista, no es otra que ridiculizar y burlarse del conjunto de políticos y votantes de derecha.

En numerosas ocasiones el periodista opta por presentar la cita implícita sin marcas tipográficas, obligando entonces al lector a servirse de sus conocimientos extralingǘsticos previos sobre una determinada realidad, de su capacidad de asociación inter y transtextual para "reconocer las implicacionas ajenas encubiertas" (Méndez, 1998:147). Como se desprende de lo dicho anteriormente, esto dista frecuentemente de constituir una tarea fácil. Comprobémoslo en el siguiente fragmento en el que se realiza un análisis simplista, que linda en la caricatura, de la filosofía política del líder de Italia dei Valori, Antonio Di Pietro:

(37) [...] Lui rilancia sempre: per la sua lista vuole soltanto candidati con la fedina penale pulita. Mani e piedi puliti. Si lamenta per il poco spazio concesso ai partiti minori ma è sempre in televisione. (Corriere della sera, 10-03-08, 11)

La presencia del sintagma léxico-semántico "mani e piedi puliti" parece desafinar en la línea discursiva del texto y el lector tendrá que desplegar buenas dosis de ingenio para descubrir por qué el periodista emplea tal sintagma aparentemente "sin venir a cuento". La ruptura de la homogeneidad léxico-semántica en el discurso es el indicio justo para sospechar que el periodista está citando implícitamente algo fuera del texto, cuya relación con el mismo sólo la perspicacia pragmática del lector conseguirá descodificar, facilitando la interpretación exacta de la cita implícita y logrando la efectividad del mensaje. ${ }^{14}$

14 A la luz de lo anterior, al lector mínimamente informado sobre los quehaceres de la política italiana en los últimos 20 años, no le resultará difícil asociar que el deseo manifiesto de Di Pietro, según el periodista, de que los candidatos estén limpios, en todos los sentidos de la palabra, no es más que una alusión indirecta al proceso de investigación denominado "Mani Pulite" que puso al 
La estrategia formal del entrecomillado, radicada en la prensa actual, hace las veces de toma de posición del periodista, que "habla" a través de palabras de otro (a menudo no identificable en el texto), seleccionadas con esmero para transmitir una representación de los hechos que, aún reflejando la orientación ideológica de quien escribe, parece a simple vista totalmente impersonal y objetiva. Pero, como hemos señalado en varias ocasiones, el periodista tiende a plasmar su personal punto de vista, recurriendo a la ironía suscitada gracias al conjunto de creencias, presuposiciones y opiniones que comparte con el lector.

Recordemos a este respecto lo que Ducrot (1984) sostiene acerca de la argumentación en la lengua; según él todo enunciado, plantea dos niveles: lo que se enuncia de manera explícita (la información trasmitida) y lo que se dice de forma implícita, que correspondería a la enunciación presupuesta y que requiere de un esfuerzo de interpretación para su exacta comprensión. De ahí que a menudo el texto nos lleve a analizar lo "no dicho", ese nivel implícito de la significación, que nos permite recobrar la situación de la enunciación original.

En las citas no expresas o encubiertas el sujeto locutor reproductor se vale a menudo de la ironía como arma defensiva para no tener que acarrear con la responsabilidad del enunciado, puesto que, como venimos señalando, la responsabilidad comunicativa del locutor se genera única y exclusivamente de lo que dice de forma explícita (explicaturas) aunque en ocasiones también de lo que transmite por medio de presuposiciones. Se trata de formas de comunicación codificada. A su vez, las implicaturas conversacionales, siguen el proceso comunicativo ostensivo-inferencial propugnado por Sperber y Wilson, que es el que le permite al lector comprender el sentido del mensaje por vía deductiva.

Veamos un ejemplo de cómo funciona este tipo de comunicación en una secuencia italiana, en la que el periodista de Il Giornale, se desdobla, valiéndose de una expresión de Walter Veltroni, "ma anche" que se convirtió en un leit motiv durante la campaña electoral. Lo que interesa resaltar es que el periodista evoca lo que dijo Walter Veltroni, animado por una especie de talante dialogante a lo Zapatero, pero aportando una nueva significación que deforma intencionalmente el discurso original, ya que lo que se pretende es mostrar una actitud negativa ante el mismo. ${ }^{15}$

descubierto el caso más grave de corrupción política en la historia de la Republica Italiana, Tangentópolis. Con este apodo de "Ciudad de los sobornos", se denominó a la ciudad de Milán a principios de los años noventa, por ser el epicentro de toda la corrupción institucionalizada que acabó barriendo judicial y políticamente a toda una generación política y al propio régimen que había gobernado el país durante más de cuarenta años. Precisamente Di Pietro, por aquel entonces fiscal, fue el principal encargado de desmontar dicha trama encabezando una investigación que, a la postre, expondría a los ojos de la sociedad italiana las numerosas prácticas corruptas que eran habituales en la política italiana.

15 Recordemos que Il Giornale es un diario posicionado ideológicamente a derechas, de propiedad de Silvio Berlusconi, el adversario político de Walter Veltroni, líder del Partito Democratico $(\mathrm{Pd})$ en las últimas elecciones generales italianas. 
(38) Liste chiuse, "ma anche" aperte. Candidature decise, "ma anche" no. Porte sbarrate, "ma anche" spalancate. Non sappiamo se il Pd sarà a favore del lavoro flessibile, ma di sicuro una cosa flessibile ce l'ha: il segretario. Un giorno chiude le liste, chi è dentro è dentro chi è fuori e fuori. Il giorno dopo le riapre. Il giorno seguente le chiude di nuovo. Ma cosèe, Veltroni, il candidato premier o il portiere di un condominio? (Il Giornale, 7-03-11, 7)

Se trata por lo tanto de un ataque al contenido del discurso de Veltroni y de su excesivo celo en contentar a todos los electores. Se pretende poner en tela de juicio su falta de congruencia, su afán por demostrarse conciliante ante opciones contrapuestas entre sí. Hay quien piensa que es más funcional hacer la caricatura de los aspectos físicos y mímicos, pero sin lugar a dudas, son los tics y clichés lingüísticos y retóricos los que tienen un mayor impacto ridiculizador. Es una forma mucho más efectiva de poner en ridículo a los políticos, porque significa atacar la figura y el contenido de su discurso, embistiendo contra su forma, su estilo, subrayando y amplificando aspectos del mismo con intención cómica. La ironía que surge tiñe el perfil del personaje de connotaciones punzantes que llegan incluso a ser mordaces.

En algunos casos, la ironía y la sátira han sabido mofarse de algunas expresiones hasta el punto de hacerlas inservibles e invalidarlas, como por ejemplo el famoso "mi consenta" que Berlusconi no puede utilizar sin desencadenar una carcajada general. ${ }^{16}$

En otras ocasiones puede suceder que la persona objeto de la ironía sepa reaccionar y usar el tic lingǘstico a su favor. Es lo que ha pasado en Italia con la expresión del cómico Maurizio Crozza, que varios meses antes del comienzo de la campaña electoral e incluso durante la misma, creó una expresión comodín que atribuyó a Walter Veltroni; dicha expresión era la que reproduce el fragmento de Il Giornale: ma anche. Desde ese momento, en la red se propagó el término maanchismo. Recorrer la historia del nacimiento de dicha expresión y su difusión, analizando los diálogos del cómico-imitador Crozza-Veltroni, comprobar que efectivamente en el discurso de Veltroni dicha fórmula conectiva halla amplio espacio y a continuación intentar comprender su papel retórico y semántico, implica asimismo que asistimos a un proceso en el que se le da un vuelco a la intención original del sujeto reproducido para ridiculizarlo.

La transtextualidad, la conexión dialógica entre diversos textos, se vuelve una característica esencial del periodismo. La procedencia de dichos textos puede ser múltiple: puede tratarse de libros, de otros artículos de periódico, de declaraciones de políticos, de eslóganes, de canciones, de películas etc. El periodista invoca continuamente a otros contextos y a otros co-textos. Esto es lo que sucede

16 Se trata de una expresión que Berlusconi usaba a menudo durante su segunda legislatura como Presidente del Consiglio italiano cuando se dirigía a exponentes de la oposición, como Massimo D'alema en el Parlamento italiano. 
en un caso como el siguiente, extraído nuevamente del provechoso artículo de Miguel Mora Berlusconi, otra vez:

(39) La canción no dice la verdad. El Caimán no se va. El Caimán ha vuelto. Ahí está, ocupando de nuevo las portadas de los periódicos del mundo entero. ( $E l$ País, 20-04-2008, 15)

Con el fin de atraer a un lector y convencerlo acerca de una determinada verdad, el periodista, amparándose en las estrategias de persuasión publicitarias, recurre a la fuerza que imprime el lenguaje figurado. Así, a menudo, en sus titulares o en los subtítulos, al igual que hace el publicitario en el eslogan, se desvía del uso corriente de la lengua introduciendo sintagmas cargados de densidad semántica que potencian el carácter enigmático del discurso. El lector detiene su atención ante un mensaje que le produce extrañeza y que le desafía psicológicamente. Si el lector resuelve el misterio probablemente se verá motivado a seguir leyendo el resto del artículo.

Es el efecto pretendido y logrado en las primeras líneas del fragmento propuesto. El lector no consigue ver límpidamente la conexión entre el título del mismo, Berlusconi, otra vez, y lo que sucede en las primeras líneas del artículo. En su cabeza probablemente se formulará una pregunta como ¿Quétiene que ver Berlusconi con un Caimán? Para descubrirlo deberá echar mano de sus recuerdos o conocimientos previos para contextualizar que "El Caimán" es el apodo del político que en la película de Nanni Moretti "Il Caimano", encarnaba la figura de Silvio Berlusconi. ${ }^{17}$ No obstante, el apodo de "Caimán” esconde y sugiere a la vez una mayor voracidad y agresividad, propias de este animal. Dichas características son las que presentaba el protagonista máscara de la película, en la que se realizaba una denuncia satírica sobre el poder de los medios de comunicación en manos de Berlusconi. Esta es la versión de Berlusconi que a Miguel Mora le interesa destacar y en la que hace más hincapié.

Pero el texto presenta una doble cita implícita, lo cual no ha de extrañar, puesto que, lo hemos dicho ya, la transtextualidad forma parte esencial de los

17 El periodista no elige casualmente este apodo, aunque habría podido elegir otros de entre la amplia lista de sobrenombres que en la esfera mediática se ha ido ganando Berlusconi, desde el más popular "Berlusca", pasando por el caricaturesco "Nano" por su altura reducida, hasta llegar al más refinado "Cavaliere".

La atribución de apodos a los políticos es moneda corriente en todos los países. En España, por ejemplo, Zapatero fue bautizado como "Bambi”, por su carácter risueño y blando en un principio, por Alfonso Guerra cuando en tiempos de la oposición socialista el actual presidente se ofrecía a firmar cuantos pactos fueran posibles con el PP.

Curiosamente la prensa extranjera suele dejar invariado los sobrenombres de los políticos. Así vemos que los periodistas italianos también denominan a Zapatero en Italia, Bambi, Mr. Bean o el más frecuente Zorro. "Il Bambi, como lo chiamavano quattro anni fa e ora nessuno osa più" (Corriere della sera, 10-03-08, 11); "Lui che non ha voluto in lista il pur pacatissimo Enrico Boselli si appassiona al leader che firma come Zorro?” (Il Giornale, 11-03-08, 7) 
textos periodísticos. Así en el texto resuena también, el estribillo de una canción colombiana, muy conocida en España, "Se va el caimán” de José María Peñaranda, que lógicamente, no contenía ningún tipo de referencia a Berlusconi cuando fue compuesta en 1941. Como venimos comentando, el periodista se apropia, modifica y en definitiva, manipula los enunciados originarios, adaptándolos para que secunden sus intenciones argumentativas. Aquí la canción sirve para potenciar la significación y simultáneamente añade una refutación que $\mathrm{Gu}$ tierrez Ordóñez denomina negación polémica ${ }^{18}$, dado que la secuencia contradice la opinión de un enunciador explícito, en este caso José María Peñaranda, que en la canción afirmaría que síse va el caimán. Por lo tanto en la negación quedaría plasmado el carácter polifónico que presenta cualquier enunciado.

Llegados a este punto queda claro que si el lector no tiene conocimiento de que en Italia en el año 2006 se realizó una película en la que el protagonista enmascaraba a Berlusconi para ridiculizarlo será muy difícil que reconstruya las implicaciones que presenta el texto y que reconozca la cita implícita. Por eso, poco después el periodista, consciente de dicha posibilidad, deshace el anonimato y la ambigüedad ofreciendo la clave de lectura, pues hace mención directa del nombre del Caimán:

(40) A sus 71 años, con su inimitable récord de 93 procesos judiciales abiertos y cero condenas firmes a la espalda, el señor Berlusca, Il Cavaliere, Silvio, ha regresado, al único poder que le faltaba, el poder político.

Las marcas de heterogeneidad mostrada pueden afectar también a palabras extranjeras que se cuelan en el texto periodístico y confieren exotismo o dan un halo de prestigio sobre todo cuando la cultura que viene adosada a la lengua también lo es, piénsese en el francés. La musicalidad de la palabra extranjera es valor añadido a la percepción del lector. Pero además el texto se impregna de nuevas implicaciones, pues las palabras vehiculan, los valores socio-culturales del país de origen:

(41) [...] Ri-Zapatero. Con qualche se e qualche ma. Proiezioni della tv di Stato, olé. Sondaggio di Antenna 3, olé. Exit poll di Telecinco e della Cuatro, olé, olé.

18 Así lo explica Salvador Gutiérrez Ordóñez: "En la argumentación contradictoria se presentan dos componentes ordenados en sucesión, de los cuales el segundo presenta algún tipo de oposición, perenne o circunstancial, respecto al primero. La manifestación prototípica la constituyen las estructuras adversativas. Las cotorras hablan, pero no piensan. Las secuencias con negación polémica son otro ejemplo característico: niegan otra opinión explícita o implícita. Imaginemos dos situaciones posibles de una misma discusión. En la primera ambos componentes se hallan explícitos: - Mañana televisan el partido. - No lo televisan. Pero imaginemos Mañana no televisan el partido. Una de las razones por las que se puede emitir este enunciado es que alguno de los asistentes haya dicho con anterioridad, o simplemente piense, que el partido se transmitiría. Desde el punto de vista pragmático y conversacional, a toda refutación le ha de seguir una justificación que apoye la postura del argumentador contradictorio.” Gutiérrez (2003: 4) 
Il $\underline{B a m b i}$, como lo chiamavano quattro anni fa e ora nessuno osa più, si gode la rivincita chiuso fino all'ultimo nel suo ufficio del quarto piano, al numero 70 della calle. (Corriere della sera, $10-03-08,11$ )

(42) Appena chiuse le urne, alle 20, gli exit poll promettevano una "goleada" di voti, per José Luis Rodríguez Zapatero. [...] Sul fronte opposto, dal 2000, quando il popolare José María Aznar batté Joaquin Almunia per kappaò. (Corriere della Sera, 10-03-08, 2)

(43) La parola d'ordine, tanto, l'ha già data Maurizio Crozza due anni fa: Zapatero, L'un per cento de tu carisma me serve aqu1!!!! (Il Giornale, 11-03-08, 7)

La presencia de estos extranjerismos, es algo usual para tanto en los textos españoles como en los italianos, aunque éstos últimos son mucho más permeables a la influencia de lenguas extranjeras. De todas formas el uso de un idioma extranjero no parece entorpecer la comunicación sino todo lo contrario, pone de manifiesto con mayor inmediatez las circunstancias que rodean un acontecimiento enriqueciendo con detalles connotativos la información dada.

Es natural que cuando el periodista cita sujetos invisibles, la voz que se manifiesta en el texto sea detectable a través de la elección léxica que lleva a cabo el locutor, que tiende a plasmar, entre otros, el registro lingüístico propio del sujeto aludido. Además de transmitir una mayor implicación emotiva el discurso se contagia entonces de las formas de la oralidad coloquial. Dicho efecto se logra sustituyendo los verba dicendi con verbos más expresivos, elocutivos, que, si bien introducen el discurso, subrayan una determinada actitud o intención del locutor:

(44) Rutelli la mette così. (Corriere della sera, 22-04-08, 2)

(45) Si fanno sentire Rifondazione e i Verdi. (Il Giornale, 12-04-08, 6)

(46) A destra cè chi tifa per Spinetta. (La Repubblica, 26-03-08, 2)

(47) Y repartió tanta cera contra Aguirre como ideología, algo muy poco habitual en él. (El País, 20-04- 07, 10)

(48) Camps trató de minimizar la bronca. (El País, 20-04-07, 11)

Como hemos podido observar en nuestro recorrido por las citas no expresas, la multiplicidad de variantes que entran en juego y la diversidad de intenciones que pone de manifiesto el periodista al valerse de ellas, hacen de esta forma de citación "atípica", un interesantísimo campo de observación de los mecanismos de manipulación presentes en el texto periodístico, y desde luego lo sostenido hasta ahora no agota en absoluto sus posibilidades de investigación. 


\section{CONSIDERACIONES FINALES}

Después de lo que llevamos dicho sobre procedimientos de reproducción del discurso ajeno, sería oportuno intentar sintetizar en un breve recorrido los puntos claves que hemos tratado para sacar algunas conclusiones.

Al principio de nuestro trabajo apuntábamos a la necesidad de abordar el texto periodístico desde una perspectiva pragmática, puesto que su mensaje no se entiende sin atender a conceptos como la intención, la acción y el resultado sobre el lector. El texto periodístico no es - y lo hemos podido comprobar- simplemente un texto informativo; su elaboración está supeditada a una finalidad práctica, convencer al lector de que se dice la verdad, a la que se llega mediante otra más teórica, argumentar, para poder persuadir. Los ejemplos que hemos ido reseñando, tanto italianos como españoles, apuntan hacia la idea de que los medios de comunicación, y en particular la prensa escrita, se guían por criterios escasamente objetivos a la hora de elaborar las noticias. Los datos revelan, a este propósito, que la política editorial de la mayor parte de los periódicos analizados, aun cuando existan diferencias significativas, se inclina más por el periodismo interpretativo y de opinión que por un periodismo aséptico y estrictamente denotativo. La información se rige por la dicotomía, a favor o en contra de tal o cual fenómeno, dejando clara la postura de quién escribe, en busca del cotejo de la intervención de un personaje - sobre todo político- o de un acontecimiento determinado.

Aunque en ocasiones tanto en la prensa italiana como en la española pueden escasear las fuentes de información, lo que convierte a la noticia en producto derivado de la observación directa de los hechos por parte del periodista, hemos podido comprobar que en las secuencias reseñadas no suele ser lo más habitual. El periodista debe buscar las fuentes que le puedan facilitar más información, desinteresada y contrastada, por lo que debe recurrir a una gran variedad de fuentes. Pese a ello, hemos observado que en la práctica, la elección de las fuentes responde eminentemente a una estrategia de manipulación informativa. Al dar espacio a determinadas fuentes, e ignorar a otras, el periodista -y por extensión la línea editorial del medio para el que trabaja - consigue transmitir su propio punto de vista y su opinión sin perder la apariencia de objetividad. El periódico se presenta entonces como un mero y aséptico transmisor de información, aunque tiende a seleccionar entre sus fuentes a aquellas personas, instituciones o documentos que sabe que puede explotar en su beneficio, favoreciendo sus intereses o con los que quiere mantener buenas relaciones. Por ello reiteramos que no es infrecuente que el periodista adopte, sin declararlo, las palabras y el punto de vista de la fuente, sobre todo cuando de políticos se trata. El periodista formula entonces la noticia como propia, aunque debe dar cuenta de su origen con el doble objetivo de darle validez ante el lector y resguardar su responsabilidad enunciativa, de ahí que se apodere de un sistema conceptual ajeno reelaborándolo hasta darle una apariencia personal. 
El reconocimiento de las diferentes voces enunciativas convocadas en el discurso periodístico, la llamada polifonía, no resulta tarea fácil puesto que el sujeto encargado de hacer pasar el discurso de otros, el periodista, dificulta deliberadamente la labor, combinando las diferentes formas de citación del discurso ajeno (DD, DI, DIL, citas mixtas, citas no expresas) con la finalidad, no tanto de dar veracidad a su propio discurso, sino más bien con el objetivo de intensificar su expresividad. Es entonces cuando hacen acto de presencia los dobles sentidos, la ironía y la connotación que responden al carácter argumentativo de este tipo de textos en los que, si bien domina el compromiso enunciativo del periodista, se suceden, con diversas modalidades de atribución y de puesta en distancia, las posiciones de otros enunciadores. En dicha línea hemos constatado que la mayor parte de las citas presentes en el discurso periodístico, tanto en España como en Italia no suelen anunciarse como tales, es decir no presentan una articulación sintáctica que contribuya a determinarla como discurso referido. El lector se ve constreñido a recurrir a la información adicional que proporciona el contexto para poder interpretar una cita no expresa como tal. Por eso se afirma que la comunicación de masas - y la periodística lo es - recurre, como hemos observado, a un tipo de comunicación indirecta y ambigua con demasiada frecuencia, en la que el proceso de comunicación tiene lugar exhibiendo un indicio, una señal, un elemento lingüístico y dejando a continuación que el receptor infiera el significado coadyuvado por las implicaturas. Los actos de habla ilocutivos, cuya finalidad es convencer, desarrollar y modificar actitudes en el lector se engloban en el marco de la comunicación persuasiva, como hemos visto, predominante en las secuencias analizadas, incluso más que la puramente informativa.

Aunque en líneas generales hemos hallado más analogías que diferencias entre las formas de reproducción del discurso ajeno de textos periodísticos italianos y españoles, hemos reparado en que una de las pautas de las secuencias italianas analizadas es la presentación de la información citada casi "in medias res", sin facilitar quién está hablando, es decir sin un marco introductivo pues con frecuencia se trata simplemente de una frase nominal. Cuando el marco se explicita tampoco es extraño que se reduzca a la mención del sujeto que profiere la cita, a menudo separados entre sí únicamente a través de una coma, algo que no hemos detectado en las secuencias españolas estudiadas.

El periodístico es, en ambos países, un lenguaje de acumulación y superposición, enfatizador o atenuador según la ocasión, casi "paroxístico" que asume y deforma formas lexicales y sintácticas existentes, instrumentalizando y apropiándose de los usos y tendencias de la lengua contemporánea (neologismos, reproducción de las características de la oralidad, tecnicismos, jergas coloquiales, lenguaje retórico, extranjerismos, etc.). Por consiguiente hemos apuntado que existe un alto grado permisividad en la escritura periodística para dar cobijo a voces procedentes de lenguajes sectoriales y jergales, neologismos y palabras extranjeras, recursos éstos empleados con una precisa intención de acercamiento a la lengua oral. 
Hemos observado además que en las diferentes formas de discurso referido (DD, DI, DIL citas mixtas, citas no expresas, etc.), el entrecomillado no garantiza que las palabras citadas correspondan al pie de la letra a las palabras efectivamente proferidas en el discurso original y lo que es aún más importante que puedan recuperar la intención del discurso original. En ello coinciden las escrituras periodísticas de ambos países. Las más de las veces, las comillas son empleadas a conciencia por el periodista para precisar que no son sus palabras y de esta manera puntualiza su responsabilidad enunciativa. Pero no es ésta la única función de dicha marca tipográfica, a menudo encubre formas de heterogeneidad mostrada, que no se anuncian como citas, atendiendo a todo un abanico de intenciones comunicativas, como puede ser parodiar la forma de hablar de un grupo social, hacer aflorar puntos de vista que el sujeto reproductor no comparte o para remarcar el uso figurado que una determinada expresión tenía en el discurso original, entre otras posibilidades.

Quizás otra diferencia que habría que resaltar, entre el lenguaje periodístico italiano y el español se basaría en la mayor o menor presencia de palabras extranjeras con el resultado de que en las secuencias italianas se hace un uso de extranjerismos mucho mayor que en los españoles, en función de la mayor permeabilidad que presenta la lengua común italiana a dichos vocablos.

De todo lo dicho se desprende que la interpretación del lenguaje periodístico, aunque mucho se haya avanzado en ese sentido, presenta una gran complejidad, debida en buena parte a la cantidad de elementos de todo tipo que deben ser analizados.

Nuestro propósito ha sido, como hemos destacado al comienzo de este trabajo acercarnos a los mecanismos de reproducción discursiva que adoptan culturas diferentes y del análisis resultante se corrobora la existencia de un lazo indisoluble entre el texto periodístico y el contexto cultural del país al que va destinado. Una simbiosis entre periodismo y producción cultural que acomuna a los todos los medios de comunicación. Nuestro trabajo, ya lo habíamos declarado al principio, no tenía en ningún momento el ánimo de exhaustividad. Nos movía simplemente la intención de acercarnos al análisis de los procedimientos de cita en la comunicación periodística, en una época en la que los medios de comunicación, desempeñan un papel de relieve no sólo a nivel social sino también en el plano cultural, psicológico e incluso económico.

\section{REFERENCIAS BIBLIOGRÁFICAS}

Alarcos Llorach, E., "El lenguaje de los titulares". En Lenguaje en periodismo escrito. Madrid, Fundación Juan March, 1977.

Anscombre, J.C., y O. Ducrot, La argumentación en la lengua, Madrid, Gredos, 1994. Charaudeau, P., El discurso de la información. La construcción del espejo social. Barcelona, Gedisa, 2003 
Diccionario de la Lengua Española, Real Academia Española, vigésima primera edición, Madrid, Espasa, 2000.

Ducrot, O., El decir y lo dicho, Buenos Aires, Hachette, 1984.

Faustini, G., Le tecniche del linguaggio giornalistico, Roma, Carocci, 1995.

Gutiérrez Ordóñez, S., Comentario pragmático de textos polifónicos, Madrid, Arco/Libros, 2003.

MÉNDEZ, E., "Formas de citación implícita en los textos periodísticos: Entre el uso y la mención", en Andalucía como ámbito de interés periodístico. Padilla Editores. Sevi1la, 1998.

—, “Análisis de la reproducción del discurso ajeno en los textos periodísticos", en Pragmalingüística, 7, Madrid, 1999, pp. 99-128

—, "Sobre la literalidad de la cita en los textos periodísticos" en Revista Española de Lingüistica, 29, 1, Gredos, Madrid, 1999 pp. 147-167.

Mortara Garavelli, B., "Per una tipologia del discorso riportato", en La parola d'altri, Palermo, Sellerio, pp. 17-50.

"Porcellum dubbi e borsettate: è la sindrome del rush finale" (2008) en La Repubblica. it Netmonitor. <http://netmonitor.blogautore.repubblica.it/2008/03/31/porcellumdubbi-e-borsettate-e-la-sindrome-del-rush-finale/>. Internet. 31-03-2008.

ReYes, G., Los procedimientos de cita: citas encubiertas y ecos, Madrid, Arco Libros, 1994.

—, Los procedimientos de cita: estilo directo y estilo indirecto, Madrid, Arco/Libros, 2002.

Nombre del autor: María Trinidad Frías Lebrón

Dirección-e: mfrias@alice.it

Dirección postal: $\quad$ Departamento de Lenguas, Facultad de Ciencias Políticas, Universidad de Cagliari, Viale Sant' Ignazio, 78, 09123 Cagliari, Italia

Fecha de recepción: 28/09/2010

Fecha de aceptación: 15/09/2011 
